\title{
Magnitude of dental caries and its associated factors among governmental primary school children in Debre Berhan town, Ethiopia
}

wondimeneh shiferaw ( $\square$ wshibabaw2015@gmail.com )

Debre Berhan University https://orcid.org/0000-0003-4348-591X

Yared Asmare Aynalem

Debre Berhan University

Getu Alamirew

Debre Berhan University

Rahel Mihiret

Debre Berhan University

Betiglua Dagne

Debre Berhan University

Beletech Mekonen

Debre Berhan University

Selamawet Abebe

Debre Berhan University

Research article

Keywords: Dental carries, children, associated factors

Posted Date: September 3rd, 2019

DOl: https://doi.org/10.21203/rs.2.11338/v1

License: (c) (i) This work is licensed under a Creative Commons Attribution 4.0 International License.

Read Full License 


\section{Abstract}

Background: Globally, it estimated that 2.4 billion people suffer from caries of permanent teeth and 486 million children suffer from caries of primary teeth. It has detrimental consequences on children's quality of life by inflicting pain, premature tooth-loss, and malnutrition and finally influences overall growth and development. In Ethiopia, oral health prevention and treatment gets low attention in the government and the existing dental services are private owned and expensive. Hence, the aim of this study was to assess the prevalence of dental caries and its associated factors among governmental primary school children in Debreberhan town, Ethiopia, 2019. Method- An institutional based cross-sectional study was conducted from January 30- February 14/2019. A total of 417 primary school children was select using computer generated simple random sampling and interviewed using structured and pretested questionnaires. Data was coded, entered and cleaned using epi-data version 3.1 and export to SPSS version 22 for analysis. Descriptive statistics, and binary logistic regression analysis was employed to test the association between dependent and independent variables. P-value less than 0.05 was taken as significant association. Finally, the result of this study was present by text, table and graph. Result: Out of the 396 study participants, 135 (34.1\%) had dental carries. Of these, more than half, 95(59.37\%) had pre-molar decayed. Two hundred eighty-five (72.0\%) of them were cleaned their teeth. Independent predictor of dental caries were drinking sugared tea [AOR=2.034, 95\% Cl: $(1.223-3.385)]$, and food particle on their teeth [AOR= 6.709, 95\% Cl: (3.475- 12.954)], had shown significant association with dental caries. Conclusion: The over magnitude of dental caries was $34.1 \%$, which is relatively high and found to be a public health problem. Drank sugar tea, presence of food particle or dental plaque were significantly associated with dental caries. In contrast, merchant occupation, was reduced the chance of dental caries. Give health education to minimize drank sugar tea and clean their teeth after consumption of sugar tea could be emphasize

\section{Background}

Dental caries is one of the global oral health problems, which cause the destruction of the hard parts of a tooth by the interaction of bacteria and fermentable carbohydrate (1).Now a day dental caries on the rise to become major public health problems worldwide, it estimated that 2.4 billion people suffer from caries of permanent teeth and out of them around 486 million children suffer from caries of primary teeth (2).Dental caries has detrimental consequences on children's quality of life by inflicting pain, eating and speaking, premature tooth-loss,undenutrion and finally influences overall growth and development (3-6). Although poor oral health is not life-threatening, it causes teeth pain, eating impairment, loss of tooth , delay language development, decrease educational concentration in school and has high financial burden on the families $(7,8)$.

Dental caries is a progressive infectious process with a multifactorial aetiology $(9,10)$.Dental caries has high morbidity potential (7). The frequent intake of sweets, dry mouth, and poor oral hygiene increase the chances for cavities (11). The early childhood caries pattern changes at age three and begins to affect the first and second primary molars in developing countries including Ethiopia $(12,13)$. The prevalence of 
dental caries among pre-school children of developed nations has been declining over the past few decades $(14,15)$. However it is still high among pre-schoolers of developing nations (16-18). Previous research has shown that, a study done in Thailand revealed that the magnitude of dental caries was 43.6 $\%$ (19), in china among 3 to 5 year old age was 70.4\%(20), in India 63.4\% (21), and Eastern Saudi Arabia was $73 \%(22)$.

The prevalence of dental caries in Africa was reported to be varies from 12.6- $24.1 \%$ in Nigeria $(23,24)$, $43.3 \%$ in Kenya (25), and 30.5\% in Sudan (26). According to recent community based study done in Ethiopia indicated that dental caries was $21.8 \%$ (27), in Addis Ababa among young adolescence was 47.4\% (28) and in Gonder town 36.3\% (29). Other study done in Finote Selam, Ethiopia showed that $48.5 \%$ of the students had dental caries (30). Overall ,dental caries may influence children's development and their participation in important daily activities (6).

According to the report of different study sex, age, dietary habits,education, and oral hygiene status are associated with increased prevalence of dental caries $(25,27,31)$. Likewise, the growing consumption of sugared foods in the developing world, poor tooth brushing habits, poor oral hygiene and low level of awareness about dental caries are some of the factors that increased the levels of dental decay $(23,32-$ 34). On the contrary frequent tooth brushing was a lower chance of having decayed (5).

To the best of our knowledge, in Ethiopia, few studies about demographic and socio-economic variables as risk factors of dental caries had been published $(28,29)$. However, oral health prevention and treatment has gotten low attention in the government and the existing dental services are private owned and expensive. As the finding of previous studies shows, dental caries is the public health problem among school children and there was no published research on the magnitude of dental caries in primary school children in the study area. Therefore, the objective of this study was to assess the prevalence of dental caries and its associated factors among governmental primary school children in Debre Berhan town, Ethiopia.

\section{Methods}

\section{Study design and setting}

An institution based cross-sectional study was conducted from January30-February 14/2019. This study was conducted in Debre-Berhan town primary school's students. Debre-berhan town were located in North Shoa Administrative Zone, Amhara National Regional State, Ethiopia. Located at a distance of 130 $\mathrm{km}$, North East of Addis Ababa (capital city of Ethiopia), $682 \mathrm{~km}$ of capital city of Amhara regional state Bahir Dar. The total population size of the district was putted as 108,876 out of which 49,259 were male and 59,617 were female(35). The Debre-Berhan town had 10 governmental primary schools and the total number of primary school students were 7,198 students, out of these the study subject were 3,607 students (36)

\section{Study participants}


Children from governmental primary schools students who is grade 1-8, present during the data collection period, those were lived in the study area at least for six months and were able to give response were included in the study. Children with 18 years of age and above, and those who were mentally ill, who could not reply interview and unable to hear were excluded from the study.

\section{Sample size estimation}

Sample size was calculated using single population proportion formula with an assumption of $95 \%$ confidence level, $5 \%$ degree of precision and proportion of dental caries, $21.8 \%(27)$. After adding $10 \%$ non-response rate and 1.5 design effect the final sample size of the study was 417 . Of them, 396 students provided a complete response.

\section{Sampling procedure}

Our study sample was obtained by two stage cluster sampling technique. In the first stage, out of ten governmental primary schools, four schools were selected by using simple random sampling technique and the sample size was allocated proportionally to each selected schools, based on the number of students. In the second stage, the study participants were selected from each grade and sections of the selected schools by simple random sampling technique using computer generated method proportionally to the number of students in each and sections. A list of the students was taken from their rosters in respective class.

\section{Data collection}

A data collection questionnaire was developed from different previous similar literatures $(27,30,32,37)$. A face-to-face interview structured questionnaire prepared in English, which contain socio-demographic data, and factors that contribute caries to exist among the study participants was prepared. To ensure quality of the data, the questionnaire was initially develop in English and translated to local language Amharic by expert and then back to English to ensure consistence. Dental examination was carried out for all selected children by one trained dental doctor using World Health Organization (WHO) dental caries diagnosis guide line under natural day light (38).Other than the outcome variables the data was collected by $5 \mathrm{BSC}$ nursing student. Before going to the actual data collection the questionnaire was pretested in similar setting outside the study district $5 \%(21)$ in model kutir 1 primary school. The questionnaire was modified based on the response after the pre-tested and modification was made into the final version of the data collection tool. Trained on data, collection was given to data collectors and supervisors for one day before actual data collection task and trained guide was prepared to facilitate the training. All data collectors were trained on their responsibilities for describing the purpose of the study, how to collect the data and telling clients the importance of honest and genuine reply on responding to questions. Lastly, the principal investigator was strictly follow the overall activities of the data collection on daily base to ensure the completeness of questionnaire and to give further clarification. To avoid ethical and equality issue, all 396 children with permitted consent were examined. Ethical approval was obtained from the Research Ethical Committee, college of health science, Debre Berhan University. 


\section{Data processing and analysis}

Data was coded, cleaned, entered and edited using Epi-data version 3.1 and exported to SPSS version 22 for analysis. Descriptive statistics, like frequency and percentage was used depending on the nature of the variable. All variables, which become significant with $p$ value of $\leq 0.25$ in the bivariable analysis was fitted in to the multivariable logistic regression. The $95 \%$ confidence interval and variables having $p$ value less than 0.05 in the multivariable model was consider as significantly associated with the dependent variable. Adjusted Odds Ratio (AOR) with 95\% confidence interval (Cl) was use to see the strength of the association between dependent and independent variables. Finally, finding of the study was display by using texts, tables and graph.

\section{Result}

\section{Socio-demographic characteristics of the study participants}

A total of 417 eligible primary school students were interviewed with nearly $95 \%$ response rate. The mean age of participants was 12.74 (SD \pm 2.556$)$ with range of $11-14$ years old. More than half, $218(55.1 \%)$ of students were females. Nearly half, $197(49.71 \%)$ of students were 11-14 age. Most of marital status of participant parent 293(74\%) were married. Regarding with the residency majority of participant, 334 (84.3\%) were urban (table 1).

\section{Food consumption pattern, dietary habits and practices related to oral hygiene}

According to our study most $307(77.5 \%)$ of students were get meal three times per days. Fifty-four (13.6\%) of the participants drank coffee with sugar. Most,307(77.5\%) of the students were drank soft drinks. One hundred twenty-nine (32.6\%) of the students used to eat sweet food. Majority $373(94.2 \%)$ of student often use sweet food and drinks. In our study most, 285(72.0\%) of them were cleaned their teeth. Out of them, $15(5.62 \%)$ cleaned teeth after every meal. However, nearly half $132(46.32 \%)$ of children cleaned their teeth once per days. Similarly nearly half $140(49.12 \%)$ of children were cleaned their teeth morning. Among participant 128 (44.91\%) of them were used teeth brush with paste. However, 122 (42.81\%) and 33(11.58\%) were used teeth brush with mefakia and only tooth brush, respectively to clean their tooth (Table 2)

\section{Magnitude of dental caries}

Out of the 396 study participants, 135 (34.1\%) had dental carries. More than half, 95(59.37\%) of the students had pre-molar dental carries. According to our study, 28(7.1\%) had missed teeth. Of these nearly half $12(42.86 \%)$ of the missed teeth was pre-molar (figure1).

\section{Factors associated with dental caries}

According to this study, children who drank sugared tea frequently had 2 times [AOR=2.03\% $\mathrm{Cl}$ : 1.22 ; 3.38]) a chance of developing dental caries than those who drank sugared tea rarely. Similarly, students 
who had food particle on their teeth were 7 times [AOR $=6.70,95 \% \mathrm{Cl}:(3.47 ; 12.95)]$ more likely to develop dental caries than those who did not have food particle on their teeth. However, Dental caries among children, whose parents' occupation of merchant were 53\% [AOR= 0.47, $95 \% \mathrm{Cl}$ : (0.240.91)] less likely chance of developing dental caries compared to those who had private worker parent. Similarly, Students who ate sweet foods had $57.8 \%$ less likely [AOR= $0.42,95 \% \mathrm{Cl}:(0.24 ; 0.71)$ ] a chance of developing dental caries than those who no use sweet foods (Table 3 ).

\section{Discussion}

According to this study, the prevalence of dental caries among school children was $34.1 \%$, which is higher than studies conducted in Bahir Dar (21.8\%)(27), Nigeria (24.1\%) (23) and Sudan (30.3\%) (26), but lower than other studies in Kenya $43.3 \%$ (25) and Finote-Selam (48.5\%) (30). The possible explanation about the variations might be the dental health consideration and the awareness level of most of Ethiopians; including Debre-berhan town school students is low. Other possible explanation might be the different study area and period.

Based on this study, the prevalence of dental caries was higher in male students $61(34.27 \%)$ than females 74(33.9\%). This result was not supported by the studies done in Bahir Dar (28), Finote- Salam (32) and in Kenya (30). This discrepancy might be due to other co-founding factors like brushing habit and dietary habits.

According to our study, age of participant, 34(36.56\%) participant age group 7-10 had dental caries. Grade 1-4 students 47(35.9\%) were more prevalent than grade 5-8 students 88 were (33.2). However, in Bahir Dar study, the proportion of dental caries was 33.3\% (27)in children from 6 to 10 years of age. The proportion of dental caries was 23 (31.9\%) and nine (12.2\%) among children from grade1-4 and 5-8, respectively. The possible reason might be when the age and education level increase the awareness about the dental carries and oral health may be increase.

Concerning about the residence in this study, the students who were lived in rural 25(40.32\%) had high prevalence than urban area 110(33\%). This finding was supported by studies done in Zimbabwe (39). However, this result was not in lined with Finote-Selma's study and in Uganda $(30,40)$. The possible reason may be the awareness of oral hygiene in rural is low.

According to the current study, 128(32.2\%) children used toothbrush with paste to clean their teeth whereas 122(30.8\%) children used a traditional small stick of wood (termed as Mafaqiya) made of a special type of plant to clean their teeth. However, the study done in Bahir Dar city reported that $67.6 \%$ of children cleaned their teeth using traditional small stick of wood (Mafaqiya) for maintaining oral hygiene (27). This might be due to the poor habit and improper usage of the tooth brushing sticks in the country.

Recent study, showed that more than half,95(59.37\%) of the respondents had pre-molar decayed and $28(7.1 \%)$ had missed teeth, of them about nearly half, $12(42.86 \%)$ of missed teeth were pre-molar. which is in line with a study done in Finote-Selam study, dental caries was most prevalent in pre- molar (42.2\%) 
(30),and the study done in Nigeria of which (46.5\%) was on pre-molar (23). This might be due to its first eruption and main role in mastication.

Based on this study, dental carries among not cleaned their teeth were $41(36.9 \%)$. Whereas a study done in Finote-Selam is a round $76.9 \%$ students who never brush their teeth had dental caries (30). This may be due to not knowing the advantage of brushing teeth and difference might be study area and period.

Dental caries among children, whose parents' occupation of merchant were $53 \%$ times less likely a chance of developing dental caries compared to those who had private worker. However, in other study no association between parent occupation and dental carries. Hence, further study is need to investigate the possible association of occupation and dental caries

According to this study, students who drank sugared tea frequently had 2 times more likely a chance of developing dental caries than those who drank sugared tea rarely. However, this result was not supported by other studies $(27,30)$. This might be due to the difference habits of drank sugared tea across different area of the studies and the participants these studies were not brush their teeth after drank sugared tea.

Regarding about the food particle, students who had food particle or plaque on their teeth were 7 times more likely to develop dental caries than those who did not have food particle on their teeth. This study was supported by a study done in Bahir Dar (28). According to this study, students who ate sweet foods frequently found to be 2.4 more likely to developing dental caries than those who use sugared foods sometimes. This study is in line with, the study done in Finote-Selam (30) and Kenya (25).

This research finding has provided important baseline information and evidence regarding the overall magnitude of dental caries and its associated factors, even though, there were some limitations; first, the study design is cross-sectional; hence, it does not show which one is come first effect or cause. Second, behaviour aspects of the children cannot understand merely by quantitative study. Third, detection of dental caries using dental mirror and radiology was not possible because of lack of instruments and laboratory set up.

\section{Conclusion}

The over magnitude of dental caries were $34.1 \%$, which is relatively high. Drank sugar tea, presence of food particle or dental plaque were found to be significantly associated with dental caries. In contrast, merchant occupation, was reduced the chance of dental caries.

\section{Abbreviations}

AOR: adjusted odd ratio; COR: crude odd ratio; SPSS: Social Package Statically Software; WHO: World Health Organization.

\section{Declarations}




\section{Ethics approval and consent to participate}

Ethical clearance and paper of approval was obtained from Debre-berhan University, institute of Medicine and College of health sciences. In addition, the supportive letter was written from department of pediatric and child health nursing. After that permission was obtained from the Debre-berhan Town education bureau and from each primary school. Finally, verbal informed consent was obtained from parent's to conduct the study. Verbal informed consent because in our university we obtain ethical clearance, after that we are explaining the risk and benefit of the research and then we under take data collection. Furthermore, cases of dental caries were advised to attend the nearby dental clinic.

\section{Consent for Publication}

Not applicable.

\section{Availability of data and materials}

All relevant data are in the manuscript. However, the minimal data underlying all the findings in the manuscript will be available upon request to corresponding author.

\section{Competing interest}

The authors declare that they have no competing interest.

\section{Funding}

The authors disclose that did not receipt any fund for this research, and publication of this article. This research was self-sponsored.

\section{Authors' contributions}

All authors equally participated in the design, conception, analysis, and interpretation. GA, RM, BD and WS facilitated the data collection and drafted. WS,BM,SM and YA were made critical revision the manuscript for important intellectual content. All had full access to all of the data in the study and takes responsibility for the integrity of the data and the accuracy of the data analysis. All authors read and approved the final manuscript.

\section{Acknowledgements}

The authors express their appreciation to Debre Berhan town education bureau, particularly the school directors for their kind cooperation during data collection. The authors are grateful to data collectors too.

\section{Reference}

1. report. W. http://www.who.int/mediacentre/factsheets/fs318/en. . 2015. 
2. Vos T, Abajobir AA, Abate KH, Abbafati C, Abbas KM, Abd-Allah F, et al. Global, regional, and national incidence, prevalence, and years lived with disability for 328 diseases and injuries for 195 countries, 1990-2016: a systematic analysis for the Global Burden of Disease Study 2016. The Lancet. 2017;390(10100):1211-59.

3. Dawkins E, Michimi A, Ellis-Griffith G, Peterson T, Carter D, English G. Dental caries among children visiting a mobile dental clinic in South Central Kentucky: a pooled cross-sectional study. BMC Oral Health. 2013;13(1):19.

4. Abanto J, Paiva SM, Raggio DP, Celiberti P, Aldrigui JM, Bönecker M. The impact of dental caries and trauma in children on family quality of life. Community Dentistry and oral epidemiology. 2012;40(4):32331.

5. Damyanov ND, Witter DJ, Bronkhorst EM, Creugers NH. Dental status and associated factors in a dentate adult population in Bulgaria: a cross-sectional survey. International journal of dentistry. 2012;2012.

6. Adulyanon S, Sheiham A. Oral impacts on daily performances. Measuring oral health and quality of life. 1997;151:160.

7. Moses J, Rangeeth B, Gurunathan D. Prevalence of dental caries, socio-economic status and treatment needs among 5 to 15 year old school going children of Chidambaram. J Clin Diagn Res. 2011;5(1):14651.

8. Zhang S, Liu J, Lo EC, Chu C-H. Dental caries status of Bulang preschool children in Southwest China. BMC Oral Health. 2014;14(1):16.

9. e Franco F, Costa TC, Amoroso P, Marin JM, Ávila FAd. Detection of Streptococcus mutans and Streptococcus sobrinus in dental plaque samples from Brazilian preschool children by polymerase chain reaction. Brazilian dental journal. 2007;18(4):329-33.

10. Garcla-Closas R, Garcla-Closas M, Serra-Majem L. A cross-sectional study of dental caries, intake of confectionery and foods rich in starch and sugars, and salivary counts of Streptococcus mutans in children in Spain. The American journal of clinical nutrition. 1997;66(5):1257-63.

11. AV. R. Dental caries talking with Patients. J EsthetRestor Dent. 2004;16:76.

12. Brodeur J-M, Galarneau C. The high incidence of early childhood caries in kindergarten-age children. J College of Dentists of Quebec. 2006.

13. Hallett KB, O'Rourke PK. Pattern and severity of early childhood caries. Community dentistry and oral epidemiology. 2006;34(1):25-35. 
14. Pitts N, Chestnutt I, Evans D, White D, Chadwick B, Steele J. 1 Verifiable CPD Paper: The dentinal caries experience of children in the United Kingdom, 2003. British dental journal. 2006;200(6):313.

15. Hugoson A, Koch G. Thirty year trends in the prevalence and distribution of dental caries in Swedish adults (1973-2003). Swed Dent J. 2008;32(2):57-67.

16. Wyne A. Caries prevalence, severity, and pattern in preschool children. The journal of contemporary dental practice. 2008;9(3):24-31.

17. ASKARZADEH N, Siyonat P. The prevalence and pattern of nursing caries in preschool children of. J Indian Soc Ped Prev Dent September. 2004;22(3):92-5.

18. Begzati A, Meqa K, Siegenthaler D, Berisha M, Mautsch W. Dental health evaluation of children in Kosovo. European journal of dentistry. 2011;5(1):32.

19. Prismasari S, Thitasomakul S. Factors Associated with Dental Caries of Permanent First Molars among Thai Primary Schoolchildren. Walailak Journal of Science and Technology (WJST). 2018;16(8):535-43.

20. Zhou N, Zhu H, Chen Y, Jiang W, Lin X, Tu Y, et al. Dental caries and associated factors in 3 to 5-yearold children in Zhejiang Province, China: an epidemiological survey. BMC oral health. 2019;19(1):9.

21. Maj Saravanan S, Lokesh S, Polepalle T, Shewale A. Prevalence, severity and associated factors of dental caries in 3-6 year old children-A cross sectional study. International Journal. 2014;2(6A):5-11.

22. Farooqi FA, Khabeer A, Moheet IA, Khan SQ, Farooq I. Prevalence of dental caries in primary and permanent teeth and its relation with tooth brushing habits among schoolchildren in Eastern Saudi Arabia. Saudi medical journal. 2015;36(6):737.

23. Udoye C, Aguwa E, Chikezie R, Ezeokenwa M, Jerry-Oji O, Okpaji C. Prevalence and distribution of caries in the 12-15 year urban school children in Enugu, Nigeria. Internet J Dent Sci. 2009;7(10.5580).

24. Eigbobo JO, Alade G. Dental caries experience in primary school pupils in Port Harcourt, Nigeria. Sahel Medical Journal. 2017;20(4):179.

25. Kassim B, Noor M, Chindia M. Oral health status among Kenyans in a rural arid setting: dental caries experience and knowledge on its causes. East African medical journal. 2006;83(2):100-5.

26. Nurelhuda NM, Trovik TA, Ali RW, Ahmed MF. Oral health status of 12-year-old school children in Khartoum state, the Sudan; a school-based survey. BMC oral health. 2009;9(1):15.

27. Mulu W, Demilie T, Yimer M, Meshesha K, Abera B. Dental caries and associated factors among primary school children in Bahir Dar city: a cross-sectional study. BMC research notes. 2014;7(1):949. 
28. Berhane HY, Worku A. Oral health of young adolescents in Addis Ababa-a community-based study. Open Journal of Preventive Medicine. 2014;4(08):640.

29. Ayele FA, Taye BW, Ayele TA, Gelaye KA. Predictors of dental caries among children 7-14 years old in Northwest Ethiopia: a community based cross-sectional study. BMC Oral Health. 2013;13(1):7.

30. Teshome A, Yitayeh A, Gizachew M. Prevalence of Dental Caries and Associated Factors Among Finote Selam Primary School Students Aged 12-20 years, Finote Selam Town, Ethiopia. Age. 2016;12(14):15-7.

31. Okoye L, Ekwueme O. Prevalence of dental caries in a Nigerian rural community: A preliminary local survey. Annals of medical and health sciences research. 2011;1(2):187-96.

32. Petersen PE. Improvement of global oral health-the leadership role of the World Health Organization. Community Dent Health. 2010;27(4):194-8.

33. Punitha V, Amudhan A, Sivaprakasam P, Rathanaprabu V. Role of dietary habits and diet in caries occurrence and severity among urban adolescent school children. Journal of pharmacy \& bioallied sciences. 2015;7(Suppl 1):S296.

34. Leme AP, Koo H, Bellato C, Bedi G, Cury J. The role of sucrose in cariogenic dental biofilm formationnew insight. Journal of dental research. 2006;85(10):878-87.

35. comition DBtAp. Debre Berhan town, Annual report of Debre Birhan town Administration plan comition .Amhara Region, Ethiopia:. 2018.

36. bureau DBtAe. Annual registration of Debre Birhan town Administration education bureau .Amhara Region, Ethiopia. . 2018.

37. Oliveira ER, Narendran S, Williamson D. Oral health knowledge, attitudes and preventive practices of third grade school children. Pediatric dentistry. 2000;22(5):395-400.

38. Organization WH. World Health Organization Oral Health Surveys-Basic Methods. Geneva: World Health Organization. 1997.

39. Mafuvadze BT, Mahachi L, Mafuvadze B. Dental caries and oral health practice among 12 year old school children from low socio-economic status background in Zimbabwe. The Pan African Medical Journal. 2013;14.

40. Wandera M, Twa-Twa J. Baseline survey of oral health of primary and secondary school pupils in Uganda. African health sciences. 2003;3(1):19-22.

\section{Tables}


Table 1.

\begin{tabular}{|c|c|c|c|}
\hline Variable & Category & Frequency & Percent (\%) \\
\hline \multirow[t]{2}{*}{ Sex of participant } & Female & 218 & 55.1 \\
\hline & Male & 178 & 44.9 \\
\hline \multirow[t]{3}{*}{ Age of participant } & $7-10$ & 93 & 23.48 \\
\hline & $11-14$ & 197 & 49.74 \\
\hline & $15-19$ & 106 & 26.76 \\
\hline \multirow[t]{2}{*}{ Educational status } & $1-4$ & 131 & 33.1 \\
\hline & $5-8$ & 265 & 66.9 \\
\hline \multirow[t]{5}{*}{ Educational status of fathers } & Illiterate & 78 & 19.7 \\
\hline & Can read and write & 102 & 25.8 \\
\hline & Grade 1-8 & 91 & 23.0 \\
\hline & Grade 9-12 & 66 & 16.7 \\
\hline & Diploma and above & 59 & 14.9 \\
\hline \multirow[t]{5}{*}{ Educational status of mother } & Illiterate & 130 & 32.8 \\
\hline & Can read and write & 88 & 22.2 \\
\hline & Grade 1-8 & 89 & 22.5 \\
\hline & Grade 9-12 & 60 & 15.2 \\
\hline & Diploma and above & 29 & 7.3 \\
\hline \multirow[t]{4}{*}{ Residency } & Urban & 334 & 84.3 \\
\hline & Rural & 62 & 15.7 \\
\hline & Married & 293 & 74.0 \\
\hline & Single & 5 & 1.3 \\
\hline \multirow[t]{2}{*}{ Marital status of } & Divorce & 61 & 15.4 \\
\hline & Widowed & 37 & 9.3 \\
\hline \multirow[t]{4}{*}{ Occupation of parents } & Farmer & 80 & 20.2 \\
\hline & Merchant & 131 & 33.1 \\
\hline & Government employee & 101 & 25.5 \\
\hline & private worker & 84 & 21.2 \\
\hline
\end{tabular}

Table 2. 


\begin{tabular}{|c|c|c|c|}
\hline \multicolumn{2}{|c|}{ Variable $\quad$ Category } & \multirow{2}{*}{$\begin{array}{l}\text { Frequency } \\
1\end{array}$} & \multirow{2}{*}{$\begin{array}{l}\text { Percent (\%) } \\
3\end{array}$} \\
\hline Get meal per days & Once per days & & \\
\hline & Three times per days & 307 & 77.5 \\
\hline & Four times per days & 88 & 22.2 \\
\hline \multirow[t]{5}{*}{ Ate break fast } & Bread with tea & 311 & 78.5 \\
\hline & Pasta or mokoroney & 18 & 4.5 \\
\hline & Injera with wot & 65 & 16.4 \\
\hline & Kinche & 2 & 2.05 \\
\hline & Others & 2 & 0.5 \\
\hline \multirow[t]{2}{*}{ Drink sugar tea } & Yes & 151 & 38.1 \\
\hline & No & 245 & 61.9 \\
\hline \multirow[t]{2}{*}{ Drink sugar coffee } & Yes & 54 & 13.6 \\
\hline & No & 342 & 86.4 \\
\hline \multirow[t]{2}{*}{ Drink soft drink } & Yes & 307 & 77.5 \\
\hline & No & 89 & 22.5 \\
\hline \multirow[t]{2}{*}{ Eat sweet food } & Yes & 129 & 32.6 \\
\hline & No & 267 & 67.4 \\
\hline \multirow[t]{3}{*}{ How often use sweet food } & Daily & 6 & 1.5 \\
\hline & Once per days & 17 & 4.3 \\
\hline & Occasionally & 373 & 94.2 \\
\hline \multirow[t]{2}{*}{ Food particle or plaque } & Yes & 280 & 70.7 \\
\hline & No & 116 & 29.3 \\
\hline \multirow[t]{2}{*}{ Use tooth brush } & Yes & 285 & 72.0 \\
\hline & No & 111 & 28.0 \\
\hline \multirow[t]{4}{*}{ Frequency of tooth brush } & After every meal & 15 & 3.8 \\
\hline & Twice per days & 53 & 13.41 \\
\hline & Once per days & 132 & 33.3 \\
\hline & Sometimes & 85 & 21.5 \\
\hline \multirow[t]{3}{*}{ Time of brushing } & Morning & 140 & 35.4 \\
\hline & Before bed & 1 & 0.3 \\
\hline & Mixed & 62 & 15.7 \\
\hline
\end{tabular}




\begin{tabular}{llll} 
& No fixed & 82 & 20.7 \\
\hline Type of brushing & Tooth brush with paste & 128 & 32.3 \\
\cline { 2 - 3 } & Only tooth brush & 33 & 8.3 \\
\cline { 2 - 3 } & Mefakia & 122 & 30.8 \\
\hline Charcoal & 2 & 0.5 \\
\hline
\end{tabular}

Table 3. 
No Yes COR(95\%CI AOR(95\%CI)

Educational level of participant father

\begin{tabular}{|c|c|c|c|c|}
\hline Illiterate & 51 & 27 & $2.07(0.94: 4.55)$ & $1.36(0.57: 5.12)$ \\
\hline $\begin{array}{l}\text { Can read and } \\
\text { write }\end{array}$ & 62 & 40 & $2.52(1.19: 5.34) *$ & $\begin{array}{l}\text { 1.92(0.55: } \\
6.68)\end{array}$ \\
\hline Grade 1-8 & 55 & 36 & $2.56(1.19: 5.48) *$ & $1.33(0.38: 4.61)$ \\
\hline Grade $9-12$ & 46 & 20 & $1.70(0.74: 3.87)$ & 0.99(0.29:3.34) \\
\hline $\begin{array}{l}\text { Diploma and } \\
\text { above }\end{array}$ & 47 & 12 & 1 & 1 \\
\hline
\end{tabular}

Educational level of participant mothers

\begin{tabular}{|c|c|c|c|c|}
\hline Illiterate & 84 & 46 & $2.09(0.79: 5.52)$ & $0.76(0.18: 3.18)$ \\
\hline $\begin{array}{l}\text { Can read and } \\
\text { write }\end{array}$ & 55 & 33 & $2.30(0.84: 6.23)$ & $0.94(0.22: 3.98)$ \\
\hline Grade 1-8 & 59 & 30 & $1.94(0.71: 5.29)$ & $0.74(0.18: 3.02)$ \\
\hline Grade 9-12 & 40 & 20 & $1.91(0.67: 5.45)$ & $0.93(0.24: 3.65)$ \\
\hline $\begin{array}{l}\text { Diploma and } \\
\text { above }\end{array}$ & 23 & 6 & 1 & 1 \\
\hline
\end{tabular}

Occupational of parent

$\begin{array}{lcclc}\text { Farmer } & 52 & 28 & 0.59(0.31: 1.11) & 0.51(0.24: 1.08) \\ \text { Merchant } & 90 & 41 & 0.50(0.28: 0.88) * & 0.47(0.24: 0.91 * \\ \text { Government } & 75 & 26 & 0.38(0.20: 0.70) * & 0.62(0.26: 1.46)\end{array}$

employee

$\begin{array}{lllll}\text { Private worker } & 44 & 40 & 1 & 1\end{array}$

Drink sugar tea

$\begin{array}{lccll}\text { Yes } & 86 & 65 & 1.89(1.23: 2.89) * & 2.03(1.22: 3.38) * \\ \text { No } & 175 & 70 & 1 & 1\end{array}$

Drink sugar coffee

$\begin{array}{clllc}\text { Ye } & 31 & 23 & 1.52(0.84: 2.73) & 1.23(0.61: 2.46) \\ \text { No } & 230 & 112 & 1 & 1\end{array}$

Eat sweet food

$\begin{array}{lllll}\text { Yes } & 94 & 35 & 1.61(0.39: 0.98) * & 2.42(0.24: 0.71 *\end{array}$

No $\quad 167 \quad 100 \quad 1 \quad 1$

Frequency of tooth brush

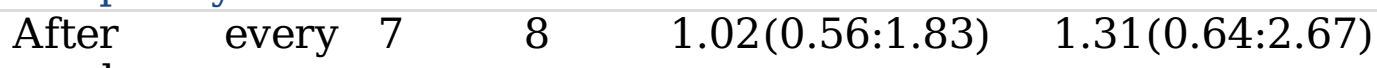

meal

Twice per days $38 \quad 15 \quad 1.99(0.65: 6.01) \quad$ 7.93(0.94:66.41

Once per days $92 \quad 40 \quad 0.68(0.32: 1.44) \quad 3.27(0.40: 26.48)$

$\begin{array}{lllll}\text { Sometimes } & 54 & 31 & 0.75(0.42-1.34) & 0.19(0.03: 1.02)\end{array}$

No $\quad \begin{array}{lll}70 & 41 & 1\end{array}$

Time of tooth brushing

$\begin{array}{lllll}\text { Morning } & 93 & 47 & 1.01(0.56: 1.83) & --- \\ \text { Before bed } & 1 & 0 & 0.87(0.49: 1.54) & 4.10(0.78: 21.43) \\ \text { Mixed } & 45 & 17 & 0.00(0.00,---) & 0.000(0.00:---) \\ \text { No fixed } & 52 & 30 & 0.65(0.32: 1.34) & 0.214(0.02: 1.71) \\ \text { No } & 70 & 41 & 1 & 1\end{array}$

Presence of food particle on teeth or plaque accumulation

$\begin{array}{lllll}\text { Yes } & 160 & 120 & 5.05(2.79: 9.12) * & 6.70(3.47: 12.95) *\end{array}$

No $\quad 101 \quad 15 \quad 1 \quad 1$ 
Health education by television

$\begin{array}{llllc}\text { Yes } & 108 & 44 & 0.68(0.44: 1.05) & 0.75(0.44: 1.28) \\ \text { No } & 153 & 91 & 1 & 1\end{array}$

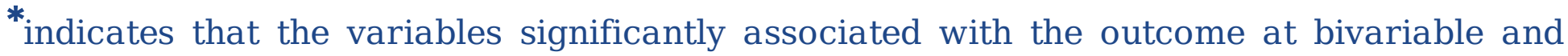
multivariable analysis $95 \%$ level of significant $(P<0.05)$.

\section{Figures}

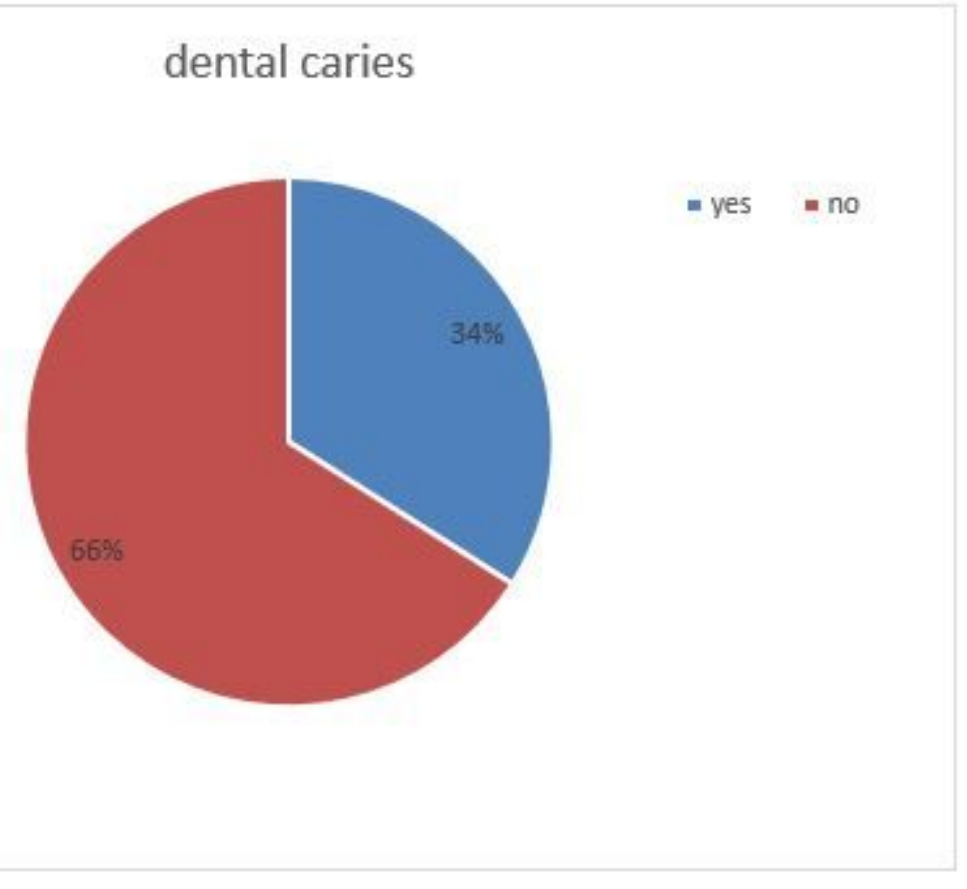

\section{Figure 1}

shows prevalence of dental caries of study participant in Debre-berhan town, Ethiopia,2019.

\section{Supplementary Files}

This is a list of supplementary files associated with this preprint. Click to download.

- STROBEchecklistcrosssectional1.doc 